\title{
Effect of $\beta$-Cyclodextrin on Phospholipids and Cholesterol of the Milk Fat Globule Membrane
}

\author{
Alonso $\mathrm{L}^{1^{*}}$, Fontecha $\mathrm{J}^{2}$ and Cuesta $\mathrm{P}^{2}$ \\ ${ }^{1}$ ConsejoSuperior de Investigaciones Científicas (CSIC, CIAL) Carretera de Infiesto s/n 33300 Villaviciosa. Asturias, Spain \\ ${ }^{2}$ Food Agricultural Products Center and Department of Animal Science, Oklahoma State University, Stillwater 74075. Oklahoma, USA
}

"Corresponding author: Alonso L, Instituto de Productos Lacteos de Asturias (CSIC) Paseo Rio Linares S7N. 33300 Villaviciosa, Asturias. Spain, Tel: +34985893206; Fax: +985892233; E-mail: lalonso@ipla.csic.es

Rec date: June 04, 2015; Acc date: June 15, 2015; Pub date: June 18, 2015

Copyright: @ 2015 Alonso L, et al. This is an open-access article distributed under the terms of the Creative Commons Attribution License, which permits unrestricted use, distribution, and reproduction in any medium, provided the original author and source are credited.

\begin{abstract}
The aim of this study was to evaluate the effect of $\beta$-cyclodextrin $(\beta-C D)$ on phospholipids and cholesterol in raw pasteurized milk with the purpuse on removal cholesterol from the milk fat. Total phospholipids decrease slightly in $\beta-C D$ treated milk but were not signinificantly affected by the effect of the $\beta-C D$. $\beta-C D$ is an effective oligosacharide for cholesterol removal from milk with more than $97 \%$ of reduction and does not affect significantly the individual phospholipids (phosphatidylcholine, phosphatidylethanolamine, sphingomyelin, phosphatidylinositol and phosphatidylserina) of the milk fat globule membrane.
\end{abstract}

Keywords: Milk fat; Phospholipids; Cholesterol; $\beta$-Cyclodextrin

\section{Introduction}

Milk contains approximately $3.4 \%$ total fat. Recent studies have given considerable evidence that phospholipids can have a positive nutritional effect on human health, such as reduction of risk of cardiovascular disease [1-5]. In the food industry, phospholipids are used as emulsifiers or emulsion stabilizers when they are complex with protein [6]. Five major classes of phospholipids are found in milk fat, and their approximate percentages are phosphatidylcholine, phosphatidylethanolamine, sphingomyelin, phosphatidylinositol and phosphatidylserina [7]. Phospholipids are located on the milk globule membrane with the cholesterol. They have both lipophilic and hydrophilic properties, and therefore, contribute significantly to the emulsification role of the membrane [8]. Today there is a growing interest in the manufacture of cholesterol reduced dairy products. Many methods for reducing cholesterol in foods have been developed, including blending in vegetable oils [9-11], extraction by distillation and crystallization [12], adsorption with saponin and digitonin [12], and removal by supercritical carbon dioxide extraction [13]. Nowdays, a number of studies have indicated that cholesterol removal from dairy product was most effectively achieved by beta-cyclodextrin $\beta$-CD $[14,15]$. The main objective of this study was to investigate the effect of the $\beta$-CD on phospholipids composition of the the milk fat globule membrane when the milk is treated with $\beta-C D$ with the purpose on removal cholesterol from the milk fat.

\section{Materials and Methods}

\section{Materials}

Raw milk was obtained from Corporacion Alimentaria Peñasanta S.A. (Asturias, Spain). Milli-Q water was obtained with a Milli-Q Plus ultra pure water system from Millipore (Milford, MA, USA). $\beta$-CD and all solvents and reagents were of analytical grade from Sigma Chemical Co., (St. Louis, MO).

\section{Standards}

Phospholipids standards, phosphatidylcholine, phosphatidylethanolamine, sphingomyelin, phosphatidylinositol, phosphatidylserina and cholesterol were purchased from Sigma Chemical Co., (St. Louis, MO).

\section{Lipid extraction}

Fat was extracted following a procedure described by International Standard Method for milk [16] using n-pentane and diethyl ether after first adding an ammonium hydroxide solution to the milk. The lipid extract obtained was stored in amber vials, exposed to a stream of $\mathrm{N} 2$ and frozen at $-20^{\circ} \mathrm{C}$ until analysis.

\section{Solid phase extraction (SPE) of PL}

Lipid sample $(500 \mathrm{mg}$ ) was dissolved in $\mathrm{ml}$ of chloroform-methanol $(2: 1, \mathrm{v} / \mathrm{v}) .1 \mathrm{ml}$ of the fat solution was applied to different SPE cartridges. A silica gel bonded column (Supelclean LC-SI, $6 \mathrm{ml}$ volume, $1 \mathrm{~g}$ sorbents, Supelco Bellfonte YSA) was used. After conditionning with hexane, the non-polar lipids were eluted with $5 \mathrm{ml}$ of hexane-diethyl ether $(8: 2, \mathrm{v} / \mathrm{v})$ and $5 \mathrm{ml}$ hexane-diethyl ether (1:1, $\mathrm{v} / \mathrm{v})$. The recovery of phospholipids was performed by using two differents conditions: the first with $4 \mathrm{ml}$ of methanol plus and the second with $2 \mathrm{ml}$ of methanol plus $2 \mathrm{ml}$ of chloroform-methanolwater $(3: 5.2, \mathrm{v} / \mathrm{v} / \mathrm{v})$. The recovered fraction was dried under a gentle stream of nitrogen and it was redissolved in $0.3 \mathrm{ml}$ of chloroformmethanol $(2: 1, \mathrm{v} / \mathrm{v})$ before injecting into the HPLC system.

\section{HPLC analysis of PL}

The HPLC analysis of phospholipids was performed using a Waters System (Alliance HPLC System 2695 separation module) coupled to a 2424 evaporative light scattering detector, data acquisitions and analysis were performed with a computer using the software version Empower 2 (Waters, Milford, MA). Separation was carried out on an Extrasil silica $(150 \times 4.0 \mathrm{~mm}$ I.D., $3 \mu \mathrm{m}$ particle size $)$ with a precolumn 
Page 2 of 3

$(2 \times 4.0 \mathrm{~mm})$ from Tracer Analitica (Teknokroma, USA) Phospholipids were separated by chromatography with isocratic elution with isopropanol-hexane-water $(55: 37: 8, \mathrm{v} / \mathrm{v} / \mathrm{v})$. The flow rate of the eluent was $1 \mathrm{ml} / \mathrm{min}$ and the column temperature was $35^{\circ} \mathrm{C}$. The volume of sample injected was $20 \mu \mathrm{l}$. The temperature of the detector was $80^{\circ} \mathrm{C}$ and the gas flow was $10 \mathrm{ml} / \mathrm{min}$. Compounds were identified by comparing the retention times of the sample peaks with those of the phospholipid standards.

\section{Determination Cholesterol by Gas Chromatography}

The technique chosen for cholesterol determination was as described by Alonso (1995) using direct injection of milk fat by capillary gas chromatography (GC). Approximately $30 \mathrm{mg}$ anhydrous milk fat and $0.1 \mathrm{ml} 5$ - $\alpha$-cholestane as internal standard $(3.5 \mathrm{mg} / \mathrm{mL}$ in hexane) was dissolved in $1 \mathrm{~mL}$ of hexane; $0.5 \mu \mathrm{L}$ of the resulting solution was injected for GC analysis. The GC analysis for free cholesterol by this direct method was on an Agilent Technology 6890 chromatograph (Palo Alto, CA) equipped with flame ionization detector. Analyses were performed using a HP-5 fused silica capillary column $(30 \mathrm{~m} \times 0.32 \mathrm{~mm}$ i.d. $0.25 \mu \mathrm{m}$ thickness). Experimental chromatographic conditions were: $\mathrm{He}$ carrier gas at 17 psi head pressure; initial column temperature $280^{\circ} \mathrm{C}$, held for $1 \mathrm{~min}$, increased to $355^{\circ} \mathrm{C}$ at $3^{\circ} \mathrm{C} / \mathrm{min}$. Injector temperature $350^{\circ} \mathrm{C}$ and detector temperature was $360^{\circ} \mathrm{C}$. Peak identification was done by comparison of relative retention times with retention times of standards. Quantification of cholesterol was conducted by comparing sample peak area with of the $5 a$-cholestane internal standard. The percentage of cholesterol reduction in milk fat was calculated by the formula [(100 - amount of cholesterol in milk fat) $x$ 100]/amount of cholesterol in untreated milk).

\section{Statistical Analysis}

All experiments were carry out three times and each experiments was analysed two times. Experimental data were treated by analysis of variance (ANOVA) using the statistical software SAS (version 8.02, SAS Institute Inc, Cary, NC, USA). Differences among treatments were determined by statistical analysis using a Student t-test where $(\mathrm{P}<0.05)$ was considered statiscally significant.

\section{Results and Discussion}

In the last decade, evidence has being gathered to suggest that an excess of cholesterol in the diet might be deleterious. A number of studies have indicated the importance of cholesterol reduction in dairy products. Cholesterol can be removed from milk and dairy products by a $\beta-C D$ a cyclic oligosacharide consisting of seven glucose unit.

There are not data in the literature concerning phospholipid compositions in milk treated with $\beta-C D$ targeting in removal of cholesterol from the milk fat. In order to evaluate the efect of $\beta$ cyclodextrin on the phospholipids, Table 1 shows the phospholipid composition of control raw milk and raw milk treated with $\beta$-CD. Analysis of variance did not reveal a significant difference $(\mathrm{P}<0.05)$ in relative composition of the differents phospholipids classes among the control milk and $\beta$-cyclodextrin treated milk. Phosphatidylethanolamine is the most predominant phospholipid representing a mean value of $35.46 \pm 0.28 \%$ in control milk and 34.12 $\pm 0.33 \%$ in treated milk. Followed by phosphatidylcholine $16.95 \pm$ $0.67 \%$ and sphingomyelin $12.61 \pm 0.42 \%$ in control milk and $15.62 \pm$ $0.59 \%$ and $13.74 \pm 0.61 \%$ in treated $\beta$-CD for those phospholipids. These three species of phospholipids represent more than $80 \%$ of the total phosphoplipids in the dairy samples [17-20].

\begin{tabular}{|l|l|l|l|l|l|l|l|}
\hline \multicolumn{2}{|l|}{ Phospholipids } & \multicolumn{3}{|l|}{} & \multicolumn{2}{l|}{ Cholesterol } \\
\hline Sample & PL (\% of sample) & PE (\% of PL) & PI (\% of PL) & PS (\% of PL) & PC (\% of PL) & SM (\% of PL) & $\begin{array}{l}\text { CH (mg/100 g milk } \\
\text { fat) }\end{array}$ \\
\hline Control Milk & $0.023 \pm 0.001$ & $35.46 \pm 0.28$ & $3.89 \pm 0.19$ & $5.38 \pm 0.48$ & $16.95 \pm 0.67$ & $12.61 \pm 0.42$ & $292.46 \pm 12.63$ \\
\hline $0.6 \% \beta-C D$ Milk & $0.022 \pm 0.001$ & $34.12 \pm 0.33$ & $3.96 \pm 0.25$ & $5.59 \pm 0.56$ & $15.62 \pm 0.59$ & $13.74 \pm 0.61$ & $8.93 \pm 0.58$ \\
\hline
\end{tabular}

Table 1: Phospholipid (PL) composition, phosphatidylethanolamine (PE), phosphatidylinositol, (PI), phosphatidylserina (PS), phosphatidylchone (PC), sphingomyelin (SM) and cholesterol of control raw milk and raw milk with $0.6 \% \beta$-cyclodextrin.

One of the reasons why the $\beta-C D$ did not affect the these components of the milk fat could be based on the fact that $\beta$-CD very specifically forms an inclusion complex with cholesterol. $\beta-\mathrm{CD}$ is a cyclic oligosacharide of seven glucose units, the molecule is doughnut shaped. The central cavity is hydrophobic, giving the molecule its affinity for non-polar molecules such cholesterol. The radious of the cavity is such as to accommodate a cholesterol molecule almost exactly, confering the highly specific nature of $\beta-C D$ ability to form an inclusion complex with cholesterol. The cholesterol is amphiphilic and the cholesterol molecules in the oil phase of an oil in water emulsion as milk tend to concentrate at the oil water interface. They are therefore accesible to $\beta-C D$ in the aqueous phase forming the insoluble inclusion complex which can be remove by centrifugation.

\section{Conclusions}

Results from the present study suggest that the treatment of whole pasteurized milk with $\beta$-CD did not affect the phospholipids compositions in the milk fat globule membrane. Therefore, this process can be applied to milk for making low cholesterol dairy products without altering any nutritional properties of phospholipids of the milk fat.

\section{Acknowledgments}

The authors thanks to the Ministry of Economy and Competitiveness from Spain (grant number AGL-2011-26713).

\section{References}

1. MacGibbon AHK, Taylor MW (2006) Composition and structure of bovine milk lipids. Advance dairy chemistry. Fox PF, McSweeney PLH New York: Springer, 1-42.

2. Bauman DE, Corl BA, Baumgard LH, Griinari JM (1998) Trans fatty acids, conjugated linoleic acids and milk fat synthesis. In Proc. Cornell Nutr. Conf., Syracuse, NY. Cornell Univ., Ithaca, NY, 95-103. 
Citation: Alonso L, Fontecha J, Cuesta P (2015) Effect of $\beta$-Cyclodextrin on Phospholipids and Cholesterol of the Milk Fat Globule Membrane. J Adv Dairy Res. 3: 140. doi:10.4172/2329-888X.1000140

Page 3 of 3

3. Parodi PW (1997) Critical review: Cow's milk fat component as potential anticarcinogenic agents. J Nutr 127: 1055-1060.

4. Willett WC (1997) Specific fatty acids and risks of breast and prostate cancer: dietary intake. Am J Clin Nutr 66: 1557-1563.

5. Eckhardt ER, Wang QH, Donovan JM, Carey MC (2002) Dietary sphingomyelin suppresses intestinal cholesterol absoption by decreasing thermodynamic activity of cholesterol monomers. Gastroenterology 122: 948-956.

6. Schneider M (2001) Phospholipids for functional foods. Eur J Lipids Sci Technol 10: 98-1001.

7. Lopez C, Briard-Bion V, Menard D, Rousseau F, Pradel P, et al. (2008) Phospholipid, sphingolipid and fatty fat globule membrane in modified diet. J Agricultural Food Chem 56: 5226-5236.

8. Fauquant C, Briard-Bion V, Leconte N (2007) Membrane phospholipids and sterols in microfiltered milk fat globules. European J Lipids Sci Technol 109: 1167-1173.

9. Palmquiest D, Stelwagen K, Ribinson P (2006) Modifying milk composition to increase use of dairy products in healthy diets. Animal Feed Sci and Technol 131: 149-153.

10. Dewhurst RJ, Shunfield KJ, Scollan ND (2006) Increasing concentrations of beneficial polyunsaturated fatty acids in milk produced by dairy cows in high forage system. Animal Feed Sci and Technol131: 168-206.

11. Krause AJ, Lopetcharat K, Drake MA (2007) Identification of the characteristics that drive consumer liking of butter. J Dairy Sci 90: 149-153.
12. Arul J, Boudreau A, Makhlouf J, Tardif R, Bellavia T (1988) Distribution of cholesterol in milk fat fractions. J Dairy Res 55: 361-371.

13. Micich TJ, Foglia TA Holsinger VH (1992) In vitro studies saponinvitamin complexation. J Agricultural Food Chem 40: 1321-1325.

14. Gonzalez-Hierro MT, Ruiz-Sala P, Alonso L, Santamaría G (1995) Extraction of ewe's milk cream with supercritical carbon dioxide. Z Lebensmittel-Untersuchung und Forschung 200: 297-300.

15. Alonso L, Cuesta P, Fontecha J, Juárez M, Gilliland SE (2008) Use of Beta-cyclodextrin to lower level of cholesterol in milk fat. J Dairy Sci, In press.

16. ISO-IDF (2001) Milk and milk products. Extraction methods for lipids and liposoluble compounds. ISO 14152; International Dairy Federation: Brussels, Belgium, p. 172.

17. ISO-IDF (2002) Milk fat. Preparation of fatty acids methyl esters. ISO 15884; International Dairy Federation: Brussels, Belgium. p. 182.

18. Alonso L, Fontecha F, Lozada L, Fraga MJ, Juárez M (1999) Fatty acid composition of caprine milk: major, branched-chain and trans fatty acids. J Dairy Sci 82: 878-884.

19. Chen H, Schwartz SJ, Spanos GA (1992) Fractionation of butter oil by supercritical carbon dioxide. J Dairy Sci 75: 2659-2669.

20. Christie WW, Noble RC, Davies G (1980) Phospholipids in milk and dairy products. J Soc Dairy Technol 40: 10-12. 